\title{
Foreign direct investment (FDI) and economic growth in China: vector autoregressive (VAR) analysis
}

\author{
Pengfei Liu*, and Han-Sol Lee \\ Peoples' Friendship University of Russia, 117198, Moscow, Russia
}

\begin{abstract}
This study examines the impact of foreign direct investment (FDI) on economic growth in China based on time series data for the period 1981-2018. For an empirical study, we used vector autoregressive (VAR) analysis. Before building our VAR model, we performed tests for unit root, normality, and heteroscedasticity to certify the data quality. The optimal lag 3 was selected using the Akaike information criterion (AIC), Schwartz (SC), and Hannan-Quinn (HQ) criteria. The Granger causality test is additionally performed. Based on the VAR model, we determined the impulse responses and variance decomposition of $\log$ FDI and $\log$ GDP in China. The results showed a positive and consistent impact of log FDI on China's economic growth. The impact in the short-term is insignificant, as it is likely that there are multiple factors drive economic growth of China besides FDI inflows. However, the impact of FDI increases to a significant level in the long-term. Which indicates that FDI is one of the main factors to enhance Chinese economy. In conclusion, we suggest a policy implication how to sustain and promote the existing positive effects of FDI inflows on Chinese economy.
\end{abstract}

Keywords: Foreign Direct Investment (FDI), Chinese economy, vector autoregressive (VAR)

\section{Introduction}

Foreign direct investment (FDI) is one of the most important driving forces of economic and social growth in developing countries. Especially, FDI played a crucial role in the transitional economies like China as the entry of foreign investment has alleviated the insufficient capital accumulation in the early stages of economic reform. The influx of foreign capital promoted employment, managerial skills, technological innovations, and healthy competition in the market economy. It is well known that influx of foreign capitals played a key role in economic development of China in the early 1990's. Even nowadays, the role of foreign capital inflows is significant as the entry of foreign capital allows their advanced technology to be spread and localized throughout the Chinese provinces, where industrial structure adjustment and upgrade of its global value chains are crucial for the further development.

* Corresponding author: 604700883@qq.com 
At the end of 2019, China has established a total of 1 million foreign-invested enterprises. Amid of global economic turbulences, for instance stagnated economic growth rate, sluggish cross-border investment, increasing uncertainty in the international environment, and intensifying competition for foreign investment, China still achieved $6.1 \%$ economic growth rate in 2019 by utilizing foreign investments, especially in advanced industries. In detail, the foreign investment is accounted for $28.5 \%$ of the total in China's high-tech industry as a whole. The inflows of FDI in advanced industries in China showed the growing tendency: the FDI inflows in high-tech manufacturing increased by $5.7 \%$; the FDI inflows in pharmaceutical manufacturing increased by $43.9 \%$; the FDI inflows in electronics and communication equipment manufacturing increased by $10.6 \%$; the FDI inflows in the hightech service industry increased by $43.4 \%$ [1].

According to Porter (1990), it is demonstrated that advanced production factors, for instance high technology, quality labor force, capital, and special knowledge become significant as the economy passed through the early developing stage so as to sustain further economic growth [2]. As mentioned above, the role of FDI to upgrade advanced industries in China is expected to be consistently significant for the further economic growth, which already achieved stark economic growth based foreign capital flows in basic industries from the early 1990's as one of the four Asian tigers. In this vein, our study empirically investigates whether the positive impact of FDI on the Chinese economy is still valid by including recent dataset for the period 1981-2018. Our article is composed as follows. The second section of our study deals with the previous studies to explore the relationship between FDI and economic growth. In the third section, we presents the VAR analysis and the results. Finally, based on the result, we provide practical policy implications of full use of FDI for future economic growth of China in conclusions.

\section{Literature review}

There are a plethora of empirical studies investigated the relationship between FDI and economic growth of recipient countries, but it shows mixed results. Makiela and Ouattara investigated the relation between FDI and economic growth in terms of transmission channels based on the data of developed and developing countries from 1970-2007. The results indicate that FDI is a partial factor to contribute on economic growth, as it helps to increase only inputs of production not factor productivity [3]. On the other hand, LUDOȘEAN explored the inter-dependency of FDI and economic growth in Romania using data for the period 1991-2009. It concludes that FDI does not lead economic growth, whereas economic growth attracts FDI [4]. In the same respect, Goh, Sam, and McNown's study on Asian economies elucidates no-evidence of long-term positive and significant effects of FDI alongside export on economic growth [5]. However, Alvarado, Iniguez, and Ponce insisted that effect of FDI varies on the recipient countries' level of economic development based on the regression analysis of 19 Latin American countries. The result shows positive and significant impact of FDI on high-income economies, while inconsistent and insignificant effect in upper-middle income economies [6].

Meanwhile, some papers are dedicated to explain the specific relation of FDI and economic growth in China. Lo, Hong, and Li explored the impact of the inward FDI on Chinese economic growth based on the data for the period 1990-2017. The result indicated that the dual effects of FDI in allocative efficiency (positive) and productive efficiency (negative), but the overall negative impacts on Chinese economy [7]. In the same line, the study of Gunby, Jin, and Reed employing a meta-analysis also demonstrated that the spillover effects of FDI are preferably exaggerated in previous studies, as inward FDI did not play a key role in Chinese economic development [8]. On the contrary, Huang, Chen, Huang, and Yang suggested different and mixed outcomes that FDI inflows have significant spill-over 
effects on Chinese economic growth, only excluding that from Hong Kong, Macau, and Taiwan [9]. Besides, based on the estimation with the data on 21 manufacturing sectors for 31 Chinese regions from 2005-2012, Tang, and Zhang insisted that whether to benefit FDI spill-over effects is dependent on the absorptive capacity of Chinese regions. Which means not volumes of inward FDI per se, but the support of other regional factors, like government FDI policy, human capital, $R \& D$, and infrastructure is decisive to create FDI spillover effects [10].

On the other hand, Zhang specifically investigated the knowledge spillover effects of inward FDI in China on research and development activities. The results demonstrated the overall positive and significant effects, but the level of effects is inconsistent across Chinese regions due to skewed distribution of inward FDI [11]. Besides, the study of Latorre, Yonezawa, and Zhou to explore the impact of FDI on advanced 21 service sectors in 11 Chinese regions found the positive impact, while the impact is still smaller than that in manufacturing sectors [12].

From the previous studies, it seems that the effect of FDI on economic growth of recipient countries and China does not reach to the single agreement as results varies on period, methodology, regions, and industries. Besides, multiple papers argues only the short-term effects of FDI. But, it is necessary to analyze long-term effects alongside short-term effects considering the time-consuming incorporation and business process.

\section{Research methods and results}

To investigate the impact of FDI on economic growth in China, we adopted vector autoregressive (VAR) analysis. We constructed the time-series data for the period 19812018. To reduce the standard deviations of the dataset, we took the log values of FDI (inflow, million \$) and GDP (constant in 2010, billion \$) [13, 14]. The specification of our model can be written as follows:

$$
\begin{aligned}
& L G D P_{t}=\alpha_{1}+\sum_{j=1}^{k} \beta_{j} \times L G D P_{t-j}+\sum_{j=1}^{k} \gamma_{j} \times L F D I_{t-j}+\varepsilon_{1 t} \\
& L F D I_{t}=\alpha_{2}+\sum_{j=1}^{k} \delta_{j} \times L F D I_{t-j}+\sum_{j=1}^{k} \varphi_{j} \times L G D P_{t-j}+\varepsilon_{2 t}
\end{aligned}
$$

where $\alpha_{1}, \alpha_{2}$ are the constants; $\beta, \gamma, \delta, \varphi$ are coefficients of endogenous variables; $\varepsilon$ are error terms.

As it is essential that all variables in the VAR methodology are stationary, we carried out a unit-root test by employing augmented dickey-fuller (ADF) including a constant at the $95 \%$ level. The null-hypothesis of the ADF test is that there is a unit-root in the time series data. Which means that our time series is stationary from the first order without time lag (Table 1).

Table 1. Testing the unit root of $\log$ GDP series and log FDI series.

\begin{tabular}{|c|c|c|c|}
\hline Lag order & $\begin{array}{c}\text { Deterministic } \\
\text { variable }\end{array}$ & $\begin{array}{c}\text { Augmented } \\
\text { Dickey-Fuller }\end{array}$ & P-Value \\
\hline 0 & Constant & -2.16 & 0.04 \\
\hline \multicolumn{3}{|c|}{$\begin{array}{c}\text { Null hypothesis: } \text { a unit root is present in log GDP series. } \\
\text { Null hypothesis is rejected at the 95\% level. }\end{array}$} \\
\hline 0 & Constant & -4.26 & 0 \\
\hline \multicolumn{3}{|c|}{ Null hypothesis: A unit root is present in log FDI series. } \\
Null hypothesis is rejected at the 95\% level. \\
\hline \multirow{3}{*}{ Test critical values: } & $1 \%$ level & -3.58 \\
\cline { 2 - 4 } & $5 \%$ level & -2.93 \\
\cline { 2 - 4 } & $10 \%$ level & -2.60 \\
\hline
\end{tabular}

Source: Own calculations. 
Next, to construct the VAR model, we selected the optimal lag based on "VAR Lag Order Selection Criteria" test based on AIC, SC, and HQ. As for the lag selection, it should be considered that the accuracy of VAR forecasts is greater in the shorter-lagged models on average, and the time-series of our model is not too long [15]. Which indicates that the shorter lag is a better resolution. As shown in Table 2, the two criteria (SC, HQ) suggest a lag length 3 for the VAR model.

Table 2. The selection of optimal lags.

\begin{tabular}{|c|c|c|c|}
\hline Lag & AIC & SC & HQ \\
\hline 0 & 0.666039 & 0.758555 & 0.696197 \\
\hline 1 & -8.873738 & -8.596192 & -8.783265 \\
\hline 2 & -9.166770 & -8.704194 & -9.015982 \\
\hline 3 & -9.827748 & $-9.180141^{*}$ & $-9.616644^{*}$ \\
\hline
\end{tabular}

Note: *Indicate the lag order selected by the criterion.

AIC (Akaike information criterion) \& SC (Schwarz information criterion) \& HQ (Hannan-Quinn) information criterion )

Source: Own calculations.

For the VAR model with lag 3, we carried out the two residual tests: normality test, and white heteroskedasticity test at the $95 \%$ level. The null hypothesis of Jarque-Bera test is that the data is normally distributed, and that of white heteroskedasticity test is that the variance for the errors are equal. As shown in Table 3, the results of the two tests did not reject the null hypothesis. Thereby, we can conclude that our data is robust to run VAR regression analysis.

Table 3. Test for residuals.

\begin{tabular}{|c|c|c|}
\hline Jarque-Bera & Degree of freedom & P-value \\
\hline 6.678485 & 4 & 0.1539 \\
\hline \multicolumn{3}{|c|}{$\begin{array}{c}\text { Null hypothesis: the data is normally distributed. } \\
\text { Null hypothesis is not rejected at the 95\% level. }\end{array}$} \\
\hline White test chi-square & Degree of freedom & P-value \\
\hline 95.14193 & 75 & 0.0582 \\
\hline \multicolumn{3}{|c|}{ Null hypothesis: the variance for the errors are equal. } \\
Null hypothesis is not rejected at the 95\% level.
\end{tabular}

Source: Own calculations.

The pairwise granger causality tests have been conducted to elucidate the causality between $\log$ FDI and log GDP. As shown in Table 4, log GDP does cause granger log FDI with no reverse effect for a lag equal to 3 . The result supported the uni-directional relationship of $\log$ GDP and $\log$ FDI. We further carried out the test to check the exceptional cases, and found out that $\log$ GDP and log FDI are bi-directionally related only in the lag 12 .

Table 4. Granger causality test.

\begin{tabular}{|c|c|c|c|c|}
\hline Null hypothesis & Lag order & Chi-square & P-Value & Result \\
\hline \multirow{2}{*}{$\begin{array}{c}\text { Log FDI does not cause granger } \\
\log \text { GDP }\end{array}$} & 3 & 3.16 & 0.37 & Accepted \\
\cline { 2 - 5 } & 12 & 66.03 & 0 & Rejected \\
\hline $\begin{array}{c}\text { Log GDP does not cause } \\
\text { granger log FDI }\end{array}$ & 3 & 28.24 & 0 & Rejected \\
\cline { 2 - 5 } & 12 & 101.60 & 0 & Rejected \\
\hline
\end{tabular}


Source: Own calculations.

The VAR estimation of log GDP and log FDI is descried in Table 5. The model can be specified as follows:

$$
\begin{aligned}
& L G D P_{t}=\alpha_{1}+\beta \times L G D P_{t-3}+\gamma \times L F D I_{t-3}+\varepsilon_{1 t} \\
& L F D I_{t}=\alpha_{2}+\delta \times L_{F D I}+\varphi+\varphi \times L D P_{t-3}+\varepsilon_{2 t}
\end{aligned}
$$

Table 5. Estimation of LFDI-LGDP VAR.

Included observations: 35 after adjustments

\begin{tabular}{|c|c|c|}
\hline & LGDP & LFDI \\
\hline LGDP(-1) & $\begin{array}{r}1.724474 \\
(0.18403) \\
{[9.37055]}\end{array}$ & $\begin{array}{c}5.175443 \\
(1.37394) \\
{[3.76688]}\end{array}$ \\
\hline LGDP(-2) & $\begin{array}{r}-1.301441 \\
(0.30646) \\
{[-4.24667]}\end{array}$ & $\begin{array}{r}-11.85334 \\
(2.28797) \\
{[-5.18072]}\end{array}$ \\
\hline LGDP(-3) & $\begin{array}{c}0.567925 \\
(0.17787) \\
{[3.19284]}\end{array}$ & $\begin{array}{c}6.647488 \\
(1.32797) \\
{[5.00575]}\end{array}$ \\
\hline LFDI(-1) & $\begin{array}{r}0.009800 \\
(0.01890) \\
{[0.51848]}\end{array}$ & $\begin{array}{c}1.278887 \\
(0.14111) \\
{[9.06303]}\end{array}$ \\
\hline LFDI(-2) & $\begin{array}{r}0.019414 \\
(0.02865) \\
{[0.67757]}\end{array}$ & $\begin{array}{r}-0.380933 \\
(0.21391) \\
{[-1.78078]}\end{array}$ \\
\hline LFDI(-3) & $\begin{array}{r}-0.025233 \\
(0.01764) \\
{[-1.43015]}\end{array}$ & $\begin{array}{c}0.074681 \\
(0.13172) \\
{[0.56696]}\end{array}$ \\
\hline $\mathrm{C}$ & $\begin{array}{c}0.043658 \\
(0.01655) \\
{[2.63778]}\end{array}$ & $\begin{array}{r}0.329736 \\
(0.12357) \\
{[2.66852]}\end{array}$ \\
\hline R-squared & 0.999709 & 0.993382 \\
\hline Adj. R-squared & 0.999647 & 0.991964 \\
\hline Sum sq. resids & 0.001694 & 0.094447 \\
\hline S.E. equation & 0.007779 & 0.058078 \\
\hline F-statistic & 16027.76 & 700.5053 \\
\hline Log likelihood & 124.2123 & 53.85081 \\
\hline Akaike AIC & -6.697847 & -2.677189 \\
\hline Schwarz SC & -6.386778 & -2.366119 \\
\hline Mean dependent & 3.393883 & 4.503882 \\
\hline S.D. dependent & 0.413786 & 0.647886 \\
\hline
\end{tabular}

Standard errors in ( ) \& t-statistics in [ ] 
Source: Own calculations.

In our VAR model, we verified the variance decomposition of log GDP and log FDI using Cholesky factors to check the explanatory power of the two variables (Table 6). It seems that for the beginning three years, the impact of log FDI on $\log$ GDP is insignificant, but it significantly grows in a long-run. In the 10 th year, log GDP is attributed to log FDI by $11.93 \%$. Thereby, it is demonstrated that the log FDI does not hold a short-term effect on $\log$ GDP, but has a long-term effect on log GDP. On the other hand, the explanatory power of $\log$ GDP to $\log$ FDI is the greatest in the 2nd and 3rd year, but continues to decrease later on. As we checked in the granger causality test, it seems that log GDP drives log FDI in the short-term. However, in the long-term, log FDI is less attracted by log GDP, but more by itself.

Table 6. The variance decomposition of $\log$ GDP and $\log$ FDI.

\begin{tabular}{|c|c|c|c|}
\hline \multicolumn{5}{|c|}{ Variance Decomposition of LGDPC: } \\
\hline Period & S.E. & LGDPC & LFDI \\
\hline 1 & 0.007779 & 100.0000 & 0.000000 \\
\hline 2 & 0.015653 & 99.87790 & 0.122096 \\
\hline 3 & 0.021302 & 98.29609 & 1.703909 \\
\hline 4 & 0.025131 & 95.30612 & 4.693883 \\
\hline 5 & 0.027639 & 92.56584 & 7.434165 \\
\hline 6 & 0.029220 & 90.62260 & 9.377396 \\
\hline 7 & 0.030348 & 89.37776 & 10.62224 \\
\hline 8 & 0.031399 & 88.68244 & 11.31756 \\
\hline 9 & 0.032583 & 88.33013 & 11.66987 \\
\hline 10 & 0.033934 & 88.06960 & 11.93040 \\
\hline \multicolumn{5}{|c|}{ Variance Decomposition of LFDI: } \\
\hline Period & S.E. & LGDPC & LFDI \\
\hline 1 & 0.058078 & 7.643323 & 92.35668 \\
\hline 2 & 0.110293 & 32.50424 & 67.49576 \\
\hline 3 & 0.141207 & 32.20173 & 67.79827 \\
\hline 4 & 0.161317 & 24.80412 & 75.19588 \\
\hline 5 & 0.178057 & 21.65653 & 78.34347 \\
\hline 6 & 0.189007 & 20.97129 & 79.02871 \\
\hline 7 & 0.195803 & 20.60444 & 79.39556 \\
\hline 8 & 0.200628 & 19.87321 & 80.12679 \\
\hline 9 & 0.205023 & 19.03277 & 80.96723 \\
\hline 10 & 0.209694 & 18.29770 & 81.70230 \\
\hline
\end{tabular}

Source: Own calculations.

Finally, we checked the impulse responses of log FDI- log GDP (Figure 1). The result (top right chart) indicated the positive impact of log FDI on log GDP in the short-term and long-term. The impact of FDI on GDP is insignificant for the first two years, but sharply grows up during the 3rd-5th years. Then it slowly goes down till the 9th years, but again increases in the 10th years. On the other hand, the impact of log GDP on log FDI shows sharp increases for the first two years, and then decreases dramatically until the 6th year. After the 6th year, it shows an increasing tendency and converges to zero. 

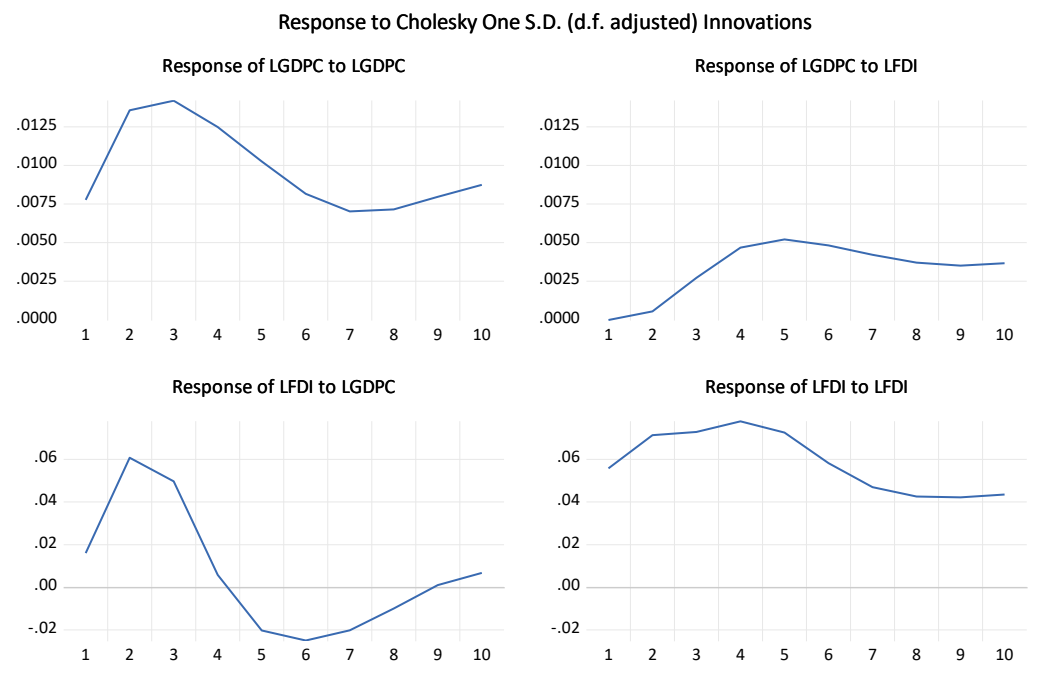

Fig. 1. Impulse functions of the VAR "LFDI-LGDP" model. Source: reproduced from EVIEW 11.

\section{Conclusion}

From our empirical study by employing VAR analysis, we identified the positive impact of FDI on economic growth in China both in the short-term and the long-term. But, the impact in the short-term seems insignificant, while it grows consistently on a significant level in the long-term. In the recent years, the development of the world economy has been characterized by deepening and reshaping the Global Value Chains (GVC). With the continuous advancement of the global economic integration process, FDI from developed countries plays an important role to achieve quality economic growth of developing countries by promoting the technological revolution and industrial reform of the underdeveloped regions.

The previous China's industrialization was able to be achieved based on the unforgettable huge sacrifices of environments and societies. Nowadays, China's economy has entered a stage requiring quality development from a rapid growth based on primary industries. It indicates that the country should amend a few practical FDI policies in a way to enhance the investment in advanced industries. China has an opportunity to induce quality FDI inflows by relaxing restrictions on key advanced industries for the further development from spillover effects, for instance financial, transportation, telecommunication, agriculture, and mining. In terms of mode of investment, alongside green-field investment, M\&A and quasi ownership of the state-owned enterprise also should be encouraged to optimize the capacity of existing uncompetitive domestic enterprises to satisfy the global standard.

In addition, China should prepare the upcoming 4th revolutionary information industries, for instance big data, cloud computing, and artificial intelligence, by cooperating with foreign investors for the next leap toward the developed economy. The era of economic growth based on cheap labor cost in primary industries is over in China. Therefore, to sustain existing positive effects of FDI inflows on Chinese economy, the government policies should be designed in a way to induce quality investments in selected potential industries, instead of to increase FDI volumes per se.

\section{References}


1. Ministry of Commerce of the People's Republic of China. Retrieved April 06, 2020, from: http://www.mofcom.gov.cn/article/tongjiziliao/v/201912/20191202923875.shtml

2. M. E. Porter, The competitive advantage of nations. Harvard business review, 68(2), 73-93 (1990)

3. K. Makiela, B. Ouattara, Foreign direct investment and economic growth: Exploring the transmission channels. Economic Modelling, 72, 296-305 (2018)

4. B.M. Ludoșean, A VAR analysis of the connection between FDI and economic growth in Romania. Theoretical and Applied Economics, 19(575), 115-130 (2012)

5. S.K. Goh, C.Y. Sam, R. McNown, Re-examining foreign direct investment, exports, and economic growth in asian economies using a bootstrap ARDL test for cointegration. Journal of Asian Economics, 51, 12-22 (2017)

6. R. Alvarado, M. Iniguez, P. Ponce, Foreign direct investment and economic growth in Latin America. Economic Analysis and Policy, 56, 176-187 (2017)

7. D. Lo, F. Hong, G. Li, Assessing the role of inward foreign direct investment in Chinese economic development, 1990-2007: Towards a synthesis of alternative views. Structural Change and Economic Dynamics, 37, 107-120 (2016)

8. P. Gunby, Y. Jin, W.R. Reed, Did FDI really cause Chinese economic growth? A meta-analysis. World Development, 90, 242-255 (2017)

9. J. Huang, X. Chen, B. Huang, X. Yang, Economic and environmental impacts of foreign direct investment in China: A spatial spillover analysis. China Economic Review, 45, 289-309 (2017)

10. Y. Tang, K.H. Zhang, Absorptive capacity and benefits from FDI: Evidence from Chinese manufactured exports. International Review of Economics \& Finance, 42, 423-429 (2016)

11. L. Zhang, The knowledge spillover effects of FDI on the productivity and efficiency of research activities in China. China economic review, 42, 1-14 (2017)

12. M.C. Latorre, H. Yonezawa, J. Zhou, A general equilibrium analysis of FDI growth in Chinese services sectors. China Economic Review, 47, 172-188 (2018)

13. UNCTAD. Retrieved March 1, 2020, from https://unctadstat.unctad.org/EN/.

14. World Bank. Retrieved March 1, 2020, from https://data.worldbank.org/.

15. R.W. Hafer, R.G. Sheehan, The sensitivity of VAR forecasts to alternative lag structures. International Journal of Forecasting, 5(3), 399-408 (1989) 